\title{
Older adults' suggestions to engage other older adults in health and healthcare: a qualitative study conducted in western Canada
}

This article was published in the following Dove Medical Press journal: Patient Preference and Adherence

Huey-Ming Tzeng'

Udoka Okpalauwaekwe ${ }^{2}$

Chang-Yi Yin ${ }^{3}$

'College of Nursing, University of Saskatchewan, Saskatoon, SK, Canada;

${ }^{2}$ Department of Academic Family Medicine, College of Medicine,

University of Saskatchewan, Saskatoon, SK, Canada; ${ }^{3}$ Taiwan History Research Foundation, Taipei, Taiwan
Correspondence: Huey-Ming Tzeng College of Nursing, University of Saskatchewan, 104 Clinic Place, Saskatoon, SK, S7N 2Z4, Canada Tel + I 7343580358 Email tzenghm@gmail.com
Aim: This qualitative study reports identified themes from suggestions made by 533 Canadian older adults, aged $\geq 65$ years in response to the open-ended question contained in a Saskatchewan Telephone Survey: "What suggestions can you make to engage someone in their health and healthcare?".

Background: In 2016, seniors accounted for $16.9 \%$ of the Canadian population. As Canadians age over the next 30 years, emergency room visits are predicted to increase by $40 \%$, outpacing the expected $30 \%$ population growth. Avoiding this increase could save the nation about $\$ 210$ million annually. A recent US study reported that the ability of seniors to carry out self-care actions predicted lower likelihood of emergency department use within 3 months.

Materials and methods: We conducted a secondary data analysis based on a provincewide, cross-sectional Saskatchewan (Canada) Telephone Survey of seniors' self-care needs conducted in March-June 2018 ( $\mathrm{N}=1,000)$. Results were analyzed using qualitative thematic content analysis. Data were charted and coded separately by two researchers; coding conflicts were resolved by consensus.

Results: A total of 533 seniors answered the open-ended question. Content analysis resulted in 11 contextual content areas with 956 total suggestions. Five key themes emerged, which included the following: feasible healthcare access, being proactive toward healthy living, having social support systems, being more open to alternative medicine, and other self-care options, and having more trained healthcare professionals to care for seniors.

Conclusion: This study reveals facilitators and challenges that currently face seniors. Seniors want equitable access to professional healthcare services and an environment that fosters self-care actions in everyday living. There is a gap in supports that would assist seniors to engage in their health and healthcare. Additional research on this issue could further inform health and human service providers to develop patient-centered strategies for promoting self-care among seniors. Keywords: patient empowerment, self-management, Canadian healthcare system, healthcare access, healthy living, social support, alternative medicine, health care professional training, active living, care navigation

\section{Introduction}

The world is having an increasing prevalence of older adults. ${ }^{1}$ The Canadian population accounts for $16.9 \%$ of older adults, projected to increase to $25 \%$ by 2036 . $^{2}$ Therefore, this growing population requires sustained supportive strategies in order to meet their health or self-care needs. ${ }^{3}$ The Canadian Institute for Health Information ${ }^{3}$ advises that Canadians aged $\geq 65$ years, are less content with the quality of healthcare received compared with their peers of the same age in ten similar countries. ${ }^{3}$ It is easy to assume that older adults 
are well cared for based on the availability of publicly funded, universal health support systems in Canada, but this is not the case in many areas, especially for those who live in rural and remote communities. Older adults in Canada commonly face chronic diseases that restrict their engagement in routine activities and, therefore, may require more attention and care support. ${ }^{3}$ The Canadian Foundation for Healthcare Improvement predicts that, as Canadians age over the next 30 years, emergency room (ER) visits will increase $40 \%$, outpacing the expected $30 \%$ growth in all population. ${ }^{4}$ Avoiding this increase could save the nation about $\$ 210$ million annually. ${ }^{4}$ As such, a recent study of 250 adults in the southern USA reported that the self-reported ability of older adults to carry out 16 of 57 self-care actions (eg., talking with providers when stopping treatment, tracking symptoms, seeking to have meaningful social connections, and planning for the future), which are required to navigate the healthcare system and maintain health, predicted a lower likelihood of ER use within 3 months. ${ }^{5}$

As a result, the purpose of this short paper is to comprehend the perspective of older adults, by analyzing their suggestions to engage others in their health and healthcare through capacity building in Saskatchewan, a province in western Canada. Based on data collected in a cross-sectional Saskatchewan Telephone Survey of older adults' perceived self-care needs in Saskatchewan, this study was a secondary data analysis of older adults' responses to the open-ended question: "What suggestions can you (older adults) make to engage someone in their health and healthcare?" The study aimed to identify challenges and barriers to promoting self-care among older adults in Saskatchewan, as well as to propose suggestions to mitigate these challenges based on recommendations from these surveyed older adults.

\section{Background Population in Saskatchewan}

In the Saskatchewan province, about half the population lives outside major cities. ${ }^{6}$ The total population in the province according to census estimation in 2016 was 1,098,352; of which, 655,313 (59.7\%) lived in small to large cities (considered as urban or urban metropolitan areas depending on population densities), 149,717 lived in towns, 47,308 lived in villages, 56,050 lived on the Indian Reserves; 176,535 lived in rural municipality; 13,429 lived in northern villages, hamlets, Crown colonies, or unorganized areas. ${ }^{7}$

Some communities are isolated and, in some cases, especially in Northern Saskatchewan, inaccessible by road. ${ }^{6}$ In many cases, these circumstances limit access to healthcare and support services (eg, lacking transportation, distance to the closest clinic or hospital), which are notably important for promoting, maintaining, and sustaining health and wellness, particularly among the elderly. ${ }^{8}$

\section{A brief overview of the Canada's healthcare system}

Medicare in Canada refers to country's publicly funded healthcare system. Each one of the 13 provinces and territories offers its own Medicare healthcare insurance plans to residents for all medically necessary hospital and physician services for free (including dental care when the service must be performed in a hospital). The federal government is responsible for, such as, setting national standards, providing funding support, and delivering healthcare services to some population groups (eg, First Nations people living on reserves, eligible veterans, and some refugee groups). ${ }^{9,10}$

The provinces and territories provide supplemental coverage to seniors, children, and social assistance recipients. Generally speaking, dental care, vision care, prescription drugs, ambulance services, and independent living and home care are not covered under Medicare..$^{9,10}$

\section{Saskatchewan government-funded health benefit}

All new Saskatchewan residents who have relocated to Saskatchewan from another Canadian province/territory, or from outside Canada (eg, foreign nationals, international students, and returning Canadians) must register themselves and their dependents for a Saskatchewan Health Card to receive health benefits. ${ }^{11}$ In Saskatchewan, some medical and community services are considered public services and are free of charge for all Saskatchewan with a valid Saskatchewan Health Card. The free medical and community services include: all medically necessary in- and outpatient services provided by physicians, physiotherapy and occupational therapy, screening mammography for women aged 50-69 years, immunizations for children and influenza vaccine every year, sexually transmitted infection treatment, human immunodeficiency virus testing, mental health services, services for treating alcohol and drug abuse problems, and problem gambling service. Selected additional health services may be provided to people recommended by the social service system (eg, dental services and prescription drug). ${ }^{12}$ Saskatchewan estimates a total of 100 hospitals/healthcare facilities throughout the province. ${ }^{13}$ Seniors aged $\geq 65$ years with a valid Saskatchewan Health Card may be eligible for Seniors' Drug Plan to pay a maximum of CAD 25 for the prescription drugs approved under Exception Drug Status. ${ }^{12}$ 


\section{Meeting older adults' self-care needs}

Support for older adults' self-care needs could lead to better patient-centered primary care interactions and acute/ emergency care transitions. Research shows that challenges in performing self-care may underpin the use of emergency care. ${ }^{5}$ Latham and Ackroyd-Stolarz ${ }^{14}$ analyzed 34,454 ER visits by older adults in four sites in Canada $(21.8 \%$ of the total ER visits in the study time period). Of these, $74.2 \%$ were triaged as urgent or emergent, and about $20 \%$ led to hospitalization. These findings imply that at least one in four ER visits made by older adults is not urgent and could be prevented. It may be noted that in the 2016 national census, $15.5 \%$ of Saskatchewan adults were aged $\geq 65$ years. ${ }^{15}$

Two recent studies identified frequently recognized self-care behaviors for navigating the healthcare system that are important to adults living in the southern USA. ${ }^{16,17}$ Researchers suggested that one approach for improving older adults' engagement in their healthcare is for healthcare providers (eg, nurses) to engage adults in identifying the self-care behaviors that are important to them and that they desire to perform. ${ }^{16,17}$ Another study ${ }^{5}$ showed that adults who indicated any of the following four self-care behaviors as being important (ie, making a list of questions and issues to discuss at the medical appointment, talking with providers when stopping treatment, seeking to have meaningful social connections, and planning for the future) were less likely to use the ER. Those who desired to have meaningful social connections as a self-care behavior were also less likely to use the ER. ${ }^{5}$

\section{Materials and methods Design}

We conducted a secondary data analysis based on a survey of older adults' perceptions of self-care behaviors needed to navigate the Canadian healthcare system and maintain health. This province-wide Saskatchewan, Canada, Telephone Survey was conducted from April 25 to June 5, 2018. The University of Saskatchewan Research Ethics Board approved this project. Participants provided verbal informed consent for their data to be used in the study as a telephone survey method was used. The study was carried out in accordance with the principles of the Declaration of Helsinki.

\section{Sample and procedures}

To achieve 1,000 completed responses, a total of 5,042 participants aged $\geq 65$ years were invited to participate. The inclusion criteria were as follows: 1) adults aged $\geq 65$ years (self-reported age), living in Saskatchewan, and 2) cognitively competent to give verbal informed consent, and to communicate in English, with the research assistants (telephone callers/interviewers) through landline or mobile telephones. The exclusion criteria were as follows: 1) adults aged $<65$ years and 2 ) not being able to communicate with the research assistants (telephone callers/interviewers) in English through landline or mobile telephones.

To recruit 1,000 cases, Saskatchewan telephone numbers $(\mathrm{N}=35,393)$ were purchased from a third-party vendor. Both landline and mobile telephone numbers were purchased. Mobile-only households in Saskatchewan accounted for 25.8\% of the sampled numbers purchased, which was in line with estimates in the 2016 Communications Monitoring Report. The survey was programmed in Sensus 6.0 and uploaded into WinCATI 6.0 for interviewing. Interviews were conducted between 9:00 a.m. and 9:00 p.m. Telephone numbers were scheduled to be called up to five times without a response before the number was discarded. Interviews were, on average, 30 minutes in duration. The response rate was $19.8 \%$ which was estimated based on completed or partially completed calls only. We were unable to document the reasons of non-respondents to the calls. Among the 1,000 older adult participants, $484(48.4 \%)$ lived in rural areas, 724 (72.4\%) were female, $581(58.1 \%)$ were aged 65 to $<75$ years, $546(54.6 \%)$ had an associate degree or higher, 924 (92.4\%) were white, and 51 (5.1\%) were immigrants. Demographic data were collected using a survey toolkit modified from a questionnaire used in a similar project conducted in southern USA., ${ }^{5,16-18}$

Free-text data collected from the open-ended question, which was part of the demographic and general health questionnaire was, "What suggestions can you make to engage someone in their health and healthcare?" were used for this analysis. Data were transcribed during the telephone survey by the trained research assistants employed by the first author's university's research laboratory.

\section{Analysis}

Data from respondents' suggestions were charted in an excel spreadsheet for thematic content analysis. Data were coded separately by the first two authors. The consensus agreement resolved coding conflicts on the contextual content after several discussions. Each senior author's response was coded to more than one contextual content area as appropriate. Then, the contextual content was grouped separately by the first two authors. Consensus agreement resolved conflicts from theme grouping after two discussions. Frequency and percentage statistics were used to present the prevalence of the identified themes and subthemes/contextual content based on 
participants' responses to the open-ended question and the demographic characteristics of the older adults.

\section{Results}

A total of 538 older adults (53.8\%) responded to the openended question considered in this study. Among these participants, 267 (49.6\%) lived in rural areas, 404 (75.1\%) were female, $318(59.1 \%)$ were aged 65 to $<75$ years, $260(48.3 \%)$ had an associate degree or higher, 493 (91.6\%) were white, and 29 (5.4\%) were immigrants. Table 1 summarizes the results of the thematic content analysis and includes selected quotes for each identified theme.

The content analysis resulted in identification of 11 contextual content areas (also called subthemes) with 956 total counts. The contextual content was grouped into five themes: 1) the government's role in providing feasible healthcare access and improved delivery of quality care; 2) capacity building; 3) family, community, and social support systems; 4) older adults being more open to alternative medicine and other self-care options; and 5) the need for government to hire more healthcare providers and provide continuing education on caring for older adults. Theme 2 - capacity building - had the most counts, about $60 \%$ of all counts.

The most frequently occurring subtheme in Theme 2 was coded as "taking responsibility for personal health and being proactive," which occurred 355 times in 956 counts (37.1\%). The second most frequently occurring subtheme, also in Theme 2, was "encouraging physical activities, weight control, and healthy eating and living" (188 counts, 19.7\%), and the third most common, from Theme 1, was "easy access to healthcare professionals and services and reduced wait times" (174 counts, $18.2 \%)$.

\section{Discussion}

We found important insights from older adults' suggestions for facilitating seniors' engagement in their personal health and healthcare in western Canada. Five themes were identified. Although we acknowledge there might have been some nuanced overlap in thematic descriptions, we chose to treat identified themes as separate rather than subthemes of one another. For example, we thought that Theme 5 may be grouped into Theme 1 as both themes addressed the Saskatchewan government. While this is a reasonable response at first blush, we chose to separate both themes to stand alone as they play out differently in a Canadian setting where these issues are intricately related, yet affects older adults variably. The reason for this also lies in the structure and practice of the Canadian healthcare system, which delineates these health concerns in its healthcare delivery and responsibility, in regard to its decentralized system of government. One could argue that there may be no differences, but history and other literature evidences support the stark differences in health systems delivery and governmental responsibility. ${ }^{10,19-22}$ As such, while Theme 1 summarizes issues bordering around governmental health structures, set-up, and the quality of access to these health systems, Theme 5 favors another issue that transcends other levels of government tiers as well as institutionalized bodies.

These findings from Themes 1-3 are corroborated in several Canadian studies. ${ }^{22-28}$ Other studies conducted in the southern USA show similar findings. ${ }^{16-18}$ These highlight the importance of these concerns to the recipients of care and more specially to the older adult population, thus, placing more emphasis on the need for older adults to take responsibility for their personal health through seeking support from their healthcare and social systems and being proactive in learning about the self-care behaviors that are needed to navigate Canada's healthcare system. This study may have also revealed a gap in the provision of adequate support or platforms where older adults in Saskatchewan can develop self-care behaviors that are needed to navigate through the healthcare system. Older adults desire a healthcare system that supports the provision of patient-centered care by providing a mechanism to learn and grow the self-care skills for better health and well-being.

For older adults to obtain needed support from their health and social systems in a timely manner, the infrastructure and capacity of the health and social services (eg, staffing and access) (Themes 1 and 5) are crucial. The government-related elements in Themes 1 and 5 intertwined with the ones in Themes 2, 3, and 4, which are associated with older adults' inner drive and desire to achieve their best possible health and well-being. As part of Saskatchewan government's Patient First commitment, the Ministry of Health's Patient and Family Advisor program has been in place and is meant to engage patients and their families in developing, implementing, and evaluating health system policies and related programs (eg, promoting patient- and family-centered care in hospital and outpatient care settings). ${ }^{29}$ This commendable effort is essential for older adults and the government to strengthen a common platform (eg, engaging patient-family advisor representatives in the government committees) that would allow both parties to co-design the health and social systems to meet the needs of Saskatchewan residents, especially during the current budget-constrained environment. 
Table I Summary of thematic content analysis of older adults' responses to the open-ended question, "What suggestions can you make to engage someone in their health and healthcare?" $(n=538)$

\begin{tabular}{|c|c|c|}
\hline Themes & Subthemes/contextual contents & Freq $^{\mathrm{a}}(\%)$ \\
\hline Theme I: The government should & I.I Creation of an equitable dental and prescription drug insurance plan & $6(0.6)$ \\
\hline provide feasible healthcare access & 1.2 Creation of more ambulance services and provision of funds for ease of transportation & $24(2.5)$ \\
\hline and improved quality of care & I.3 Provision of more healthcare services in rural and remote areas & $25(2.6)$ \\
\hline \multirow[t]{3}{*}{ delivery for older adults } & I.4 Easy access to healthcare professionals and services and reduced wait-times & $174(18.2)$ \\
\hline & & Subtotal: $229(23.9)$ \\
\hline & $\begin{array}{l}\text { Selected quotes related to Theme I: } \\
\text { "Our access is not that good ... you gotta wait for a couple of hours or a day ... takes a } \\
\text { lot of time to get (an) MRI ... there is not enough preventative medicine." } \\
\text { "Nurse practitioners' care is so much better than the doctors'. They pay more attention on } \\
\text { the patient without rushing you. It is just so much better. No time for the doctor to discuss } \\
\text { things with the patients, they are more concerned with the number of in-and-out patients." }\end{array}$ & \\
\hline \multirow[t]{5}{*}{ Theme 2: Capacity building } & 2.I Having a positive outlook on life & $30(3.1)$ \\
\hline & 2.2 Taking responsibility for personal health and being proactive & $355(37.1)$ \\
\hline & 2.3 Encouraging physical activities, weight control, and healthy eating and living & $188(19.7)$ \\
\hline & & Subtotal: 573 (59.9) \\
\hline & $\begin{array}{l}\text { Selected quotes related Theme 2: } \\
\text { "Be proactive ... stay healthy, exercise, eat good food, take frequent walks, be kind to } \\
\text { everyone, and assist neighbors ... volunteer to work." } \\
\text { "You are responsible for your own health, which includes mental, emotional, physical and } \\
\text { spiritual health ... stop smoking." } \\
\text { "Speak up for yourself and don't be afraid." } \\
\text { "Talk to your pharmacist." }\end{array}$ & \\
\hline \multirow{4}{*}{$\begin{array}{l}\text { Theme 3: Family, community, and } \\
\text { social support systems }\end{array}$} & 3.I Having individual or family support & $74(7.7)$ \\
\hline & 3.2 Engaging in community and social support systems & $56(5.9)$ \\
\hline & & Subtotal: $130(13.6)$ \\
\hline & $\begin{array}{l}\text { Selected quotes related to Theme 3: } \\
\text { "The best thing people can do is get together and get someone to come out to talk to us. } \\
\text { Talk to us about what to look for and what [not]. It would be nice to be with a group and } \\
\text { [to be] kept informed. There might be groups like that, but I don't know." } \\
\text { "It is best to have someone to check on you when you need to be checked on if you're } \\
\text { having difficulty." }\end{array}$ & \\
\hline \multirow{3}{*}{$\begin{array}{l}\text { Theme 4: Being more open to } \\
\text { alternative medicine and other } \\
\text { self-care options }\end{array}$} & $\begin{array}{l}\text { 4.I Older adults being more open-minded about alternative medicine and other self-care } \\
\text { options }\end{array}$ & $12(1.3)$ \\
\hline & & Subtotal: I2 (I.3) \\
\hline & $\begin{array}{l}\text { Selected quotes related to Theme } 4 \\
\text { "Be open minded ... give everything a try including traditional medicine." } \\
\text { "Be open minded ... you can try alternative medicine." } \\
\text { "... go to church and pray." }\end{array}$ & \\
\hline \multirow{3}{*}{$\begin{array}{l}\text { Theme 5: The government should } \\
\text { hire more healthcare providers } \\
\text { and provide continued learning in } \\
\text { caring for older adults }\end{array}$} & $\begin{array}{l}\text { 5.I Training of new healthcare personnel (ie, physicians and nurses) and re-training of } \\
\text { currently practicing healthcare professionals }\end{array}$ & $12(1.3)$ \\
\hline & & Subtotal: $12(1.3)$ \\
\hline & $\begin{array}{l}\text { Selected quotes related to Theme 5: } \\
\text { "Most healthcare providers need more training." "Doctor does not take patient's } \\
\text { concerns (seriously)." } \\
\text { "Training for taking care of seniors." } \\
\text { "Simplify communication with elderly." } \\
\text { "Need training for dealing with someone with disability." } \\
\text { "Doctors who do not make referrals." } \\
\text { "Doctors' attitudes." } \\
\text { "The system needs more health specialists to fill the gaps...especially in the rural areas } \\
\text { where we reside." }\end{array}$ & \\
\hline Sum total & & 956 \\
\hline
\end{tabular}

Notes: ${ }^{\mathrm{a}} \mathrm{Freq}=$ frequency. Each response could be coded to more than one theme and subtheme as appropriate, which resulted in a total count of 956 suggestions for the contextual content areas. 
As for the funding allocated to improve health care in Saskatchewan, the Saskatchewan governments' provincial health budget was CAD 5.77 billion in the 2018-2019 fiscal year. This was about $39 \%$ of the total government spending, a record high increase of about $2.5 \%$ from the previous fiscal year. ${ }^{30,31}$ Hickey $^{32}$ concluded that Saskatchewan provincial expenditures on healthcare have increased by substantial amounts from 1975 at $6.4 \%$ of the provincial gross domestic product (GDP) to 2004 at $10.4 \%$ of the provincial GDP. In 2004, health spending exceeded growth in the provincial economy, general government revenues, population, and inflation. Increasing health spending also has contributed to higher provincial deficits and debt. ${ }^{32}$ It is not a surprise that health costs in Saskatchewan continue to grow.

\section{Limitations}

As for the limitations of this study, the study sample only included older adults living in Saskatchewan, Canada. Due to limited literature in the subject area, this study included a limited comparison with similar studies elsewhere in the world. As such, generalization of this study's findings to different regions or countries should be done with caution. Future research is needed to understand older adults' desire to engage in their own health and healthcare across different geographical areas, healthcare systems, and ethnic groups - such as new immigrants with limited language proficiency - to better support self-care among older adults. ${ }^{18,33}$ Conducting a series of focus groups with older adults, policy makers related to health and social services, and healthcare providers in both rural and urban areas are warranted to further explore how older adults' suggestions summarized in this study could be incorporated into the healthcare and social systems, as well as, in the existing budget and resources to meet their needs for better health and well-being. Conducting provincial-wide surveys to learn older adults' priorities when seeking support from the health and social systems is desirable.

\section{Conclusion}

Older adults are considered to be the faster growing population group in Canada according to Statistics Canada; ${ }^{2,7}$ as such, attract increased health demands and attention. This study sought to identify facilitators and challenges facing older adults in rural and urban areas in Saskatchewan, especially with accessing quality healthcare services (Themes 1 and 5) and achieving competence in pursuing self-care actions (Themes 2, 3, and 4). We conclude that older adults want equitable access to professional healthcare services in Saskatchewan. Older adults also desire an environment that fosters and promotes the adoption and preservation of self-care actions in everyday life. The findings of this qualitative study provide a preliminary basis for stimulating patient-centered strategies in health service planning, delivery, and additional research on patient engagement, especially regarding the roles of healthcare professionals. Such research could have an impact on health and social policies as well as community leadership. It could also result in improved services for older adults and their families in Saskatchewan, other Canadian provinces, and beyond.

\section{Disclosure}

The authors report no conflicts of interest in this work.

\section{References}

1. World Health Organization (WHO). Global Health and Aging. Released September 2015. Available from: https://www.who.int/ageing/publications/global_health.pdf. Accessed January 19, 2019.

2. Statistics Canada. 2017. Population Projections for Canada (2013 to 2063), Provinces and Territories (2013 to 2038). Technical Report on Methodology and Assumptions. (Statistics Canada Catalogue no. 91-620-X). Available from: https://www150.statcan.gc.ca/n1/pub/91520-x/91-520-x2014001-eng.htm and https://www150.statcan.gc.ca/n1/ en/catalogue/91-620-X. Accessed February 12, 2019.

3. Canadian Institute for Health Information (CIHI). Seniors Think Canada's Health Care Systems Have Room to Improve, Survey Finds. Ottawa: Canadian Institute for Health Information; 2002. Available from: https://www.cihi.ca/en/seniors-think-canadas-health-caresystems-have-room-to-improve-survey-finds. Accessed January 18, 2019.

4. Risk Analytica. The Impact on Emergency Department Utilization of the CFHI Healthcare Collaborations and Initiatives. Canada: Canadian Foundation for Healthcare Improvement; 2013. Available from: https:// www.cfhi-fcass.ca/sf-docs/default-source/reports/risk-analytica. pdf?sfvrsn=bd41df44_2. Accessed January 18, 2019.

5. Tzeng HM, Pierson JM, Kang Y, Barker A, Yin CY. Exploring the associations between patient affect, self-care actions, and emergency room use for community-dwelling adults. J Nurs Care Qual. Epub 2018 Jul 23.

6. Nair BV, Schuler R, Stewart S, Taylor-Gjevre RM. Self-reported barriers to healthcare access for rheumatoid arthritis patients in rural and Northern Saskatchewan: a mixed methods study. Musculoskeletal Care. 2016;14(4):243-251.

7. Statistics Canada. 2016. Saskatchewan Population Report: 2016 Census of Canada. Released in September 2016. http://publications.gov.sk.ca/ documents/15/100723-Saskatchewan\%20Population\%20Report $\% 20$ for $\% 20$ the $\% 202016 \% 20$ Census.pdf and https://www12.statcan.gc.ca/ census-recensement/2016/dp-pd/prof/details/page.cfm?Lang=E\&Ge $\mathrm{o} 1=$ PR $\&$ Code $1=47 \&$ Geo $2=$ PR $\&$ Code $2=01 \&$ Data $=$ Count $\&$ SearchTe $\mathrm{xt}=$ Canada\&SearchType $=$ Begins $\&$ SearchPR $=01 \& B 1=$ All. Accessed February 12, 2019.

8. Goodridge D, Rogers M, Klassen L, et al. Access to health and support services: perspectives of people living with a long-term traumatic spinal cord injury in rural and urban areas. Disabil Rehabil. 2015; 37(16):1401-1410.

9. Government of Canada. 2016. Canada's health care System. Released February 2016. Available from: https://www.canada.ca/en/ health-canada/services/canada-health-care-system.html. Accessed February 12, 2019. 
10. Klatt I. Understanding the Canadian health care system. J Financ Serv Prof. 2000;54(5):42-51.

11. Government of Sasktchewan. Saskatchewan health cards; 2019. Available from: https://www.ehealthsask.ca/residents/health-cards. Accessed January 18, 2019.

12. Canadian Institute for Health Information (CIHI). An in-depth look at the Saskatchewan health care system. Ottawa: Canadian Institute for Health Information; 2000. Available from: https://www.cihi.ca/en/ an-in-depth-look-at-the-saskatchewan-health-care-system. Accessed January 18, 2019.

13. Government of Saskatchewan. Ministry of Health Medical Service Branch Annual Statistical Report for 2016-17; 2017. Available from: https://www.saskatchewan.ca/government/government-structure/ ministries/health. 2018. Accessed January 18, 2019.

14. Latham LP, Ackroyd-Stolarz S. Emergency department utilization by older adults: a descriptive study. Can Geriatr J. 2014;17(4):118-125.

15. Statistics Canada. 2017. Saskatchewan and Canada (table). Census Profile. 2016 Census. Statistics Canada Catalogue no 98-316-X2016001. Ottawa. Released November 29, 2017. Available from: https://www12. statcan.gc.ca/census-recensement/2016/dp-pd/prof/index.cfm?Lang=E. Accessed January 18, 2019.

16. Tzeng HM, Marcus Pierson J. Measuring patient engagement: which healthcare engagement behaviours are important to patients? $J A d v$ Nurs. 2017;73(7):1604-1609.

17. Tzeng HM, Pierson JM. What are the highly important and desirable patient engagement actions for self-care as perceived by individuals living in the southern United States? Patient Prefer Adherence. 2017; 11:181-191.

18. Tzeng HM, Okpalauwaekwe U, Yin CY, Jansen SL, Feng C, Barker A. Do patients' demographic characteristics affect their perceptions of selfcare actions to find safe and decent care? Appl Nurs Res. 2018;43:24-29.

19. Paez A, Mercado RG, Farber S, Morency C, Roorda M. Accessibility to health care facilities in Montreal island: an application of relative accessibility indicators from the perspective of senior and non-senior residents. Int J Health Geogr. 2010;9(1):52-52.

20. Penney C. Understanding accountability in the Canadian health system. Healthc Manage Forum. 2004;17(2):9-15.

21. Hebert R. An urgent need to improve life conditions of seniors. J Nutr Health Aging. 2010;14(8):711-714.

22. Bacsu JR, Jeffery B, Johnson S, Martz D, Novik N, Abonyi S. Healthy aging in place: Supporting rural seniors' health needs. Online J Rural Nurs Health Care. 2012;12(2):77-87.
23. Clark KJ, Leipert BD. Strengthening and sustaining social supports for rural elders. Online J Rural Nurs Health Care. 2012;7(1):13-26.

24. Beatty BB, Berdahl L, University of Saskatchewan. Health care and aboriginal seniors in urban Canada: helping a neglected class. Int Indigenous Policy J. 2011;2(1):1-16.

25. O'Connor D, Kelson E. Boomer matters: responding to emotional health needs in an aging Society. J Gerontol Soc Work. 2018;61(1):61-77.

26. Rozanova J, Keating N, Eales J. Unequal social engagement for older adults: constraints on choice. Can J Aging. 2012;31(1):25-36.

27. Canham SL, Fang ML, Battersby L, et al. Contextual factors for aging well: creating socially engaging spaces through the use of deliberative dialogues. Gerontologist. 2018;58(1):140-148.

28. Smith-Carrier T, Sinha SK, Nowaczynski M, Akhtar S, Seddon G, Pham TT. It 'makes you feel more like a person than a patient': patients' experiences receiving home-based primary care (HBPC) in Ontario, Canada. Health Soc Care Commun. 2017;25(2):723-733.

29. Government of Saskatchewan. Patient and Family Advisor Program; 2010. Available from: https://www.saskatchewan.ca/residents/health/ accessing-health-care-services/patient-and-family-advisor-program. Accessed January 18, 2019.

30. Baxter D. 2018. Saskatchewan spending record $\$ 5.36 \mathrm{~B}$ on health care. Released April 10, 2018. Available from: https://globalnews ca/news/4135972/saskatchewan-budget-2018-health-care/. Accessed January 18, 2019.

31. Giles D. 2018. Saskatchewan projecting $\$ 365$ M deficit in 2018-2019 budget. Released April 10, 2018. Available from: https://globalnews. ca/news/4135685/saskatchewan-budget-2018/. Accessed January 18, 2019.

32. Hickey D. 2005. Health spending in Saskatchewan: Recent trends, future options. Published by Government of Saskatchewan. Available from: https://ourspace.uregina.ca/bitstream/handle/10294/6610/SIPP\%20 The \%20Scholar\%20Series\%20Spring\%202006.pdf? sequence=1. Accessed January 18, 2019.

33. National Academies of Sciences, Engineering, and Medicine. 2018. Health Literacy and older adults: Reshaping the landscape: Proceedings of a workshop. Washington, DC: The national Academies Press. doi: https://doi.org/10.17226/25188. Available at: https://www.ncbi. nlm.nih.gov/books/NBK532464/pdf/Bookshelf_NBK532464.pdf. Accessed February 12, 2019.
Patient Preference and Adherence

\section{Publish your work in this journal}

Patient Preference and Adherence is an international, peer-reviewed, open access journal that focuses on the growing importance of patient preference and adherence throughout the therapeutic continuum. Patient satisfaction, acceptability, quality of life, compliance, persistence and their role in developing new therapeutic modalities and compounds to optimize

\section{Dovepress}

clinical outcomes for existing disease states are major areas of interest for the journal. This journal has been accepted for indexing on PubMed Central. The manuscript management system is completely online and includes a very quick and fair peer-review system, which is all easy to use. Visit http://www. dovepress.com/testimonials.php to read real quotes from published authors. 